\title{
L'Impact de la Femme sur La Civilisation du Caire Islamique
}

\author{
Radwa M. Omar \\ Lecturer of Islamic Architecture \\ Faculty of Tourism and Hotels, Suez Canal University
}

\begin{abstract}
Sommaire
Cette recherche met l'accent sur le rôle de la femme sur la civilisation du Caire à l'époque musulmane, elle avait un impact incontestables malgré les restrictions sociales imposées par les traditions; ces traces indéniables sont relatées dans les biographies qui mentionnaient les noms de certaines femmes dont l'activité politique, intellectuelle, religieuse et sociale, a forgé l'histoire du Caire; elles étaient savantes, poètes, narrateurs du hadìths, littéraires et médecins. De même, elle souligne la contribution dans les arts appliqués qui doivent beaucoup de leur prospérité aux doigts qualifiés des femmes cairotes et à leur goût manifesté dans la fabrication de céramique et de poterie, en plus, la diversité de ses produits du textile et de tapis a rendu cette industrie célèbre dans d'autres pays. En outre, la femme cairote a fourni sa part dans l'industrie de la bijouterie, elle a même développé de nouveaux types de parures, ainsi que les produits cosmétiques comme les peignes, les miroirs, les flacons de parfums et les pots de fard. D'autre part, la recherche met en évidence son impact sur l'architecture islamique; ce qui est retraçable dans la conception de logement qui visait à protéger la vie privée de la femme, par conséquence, la maison était aménagée d'une cour centrale à ciel ouvert, les fenêtres étaient couvertes par des mašrabiyyas (fenêtre grillagées de bois tourné), encore, une aile séparée y était consacrée (le harem), elle avait également un impact sur l'architecture de certaines institutions religieuses importantes telles que les hāanqāhs (maison soufie), les mosquées, les madrasas et les mausolées comme celui de 'Sayyida Ruaqya' que 'Alam al- Amīriyya' a ordonné de le faire bâtir et le mausolée de 'Šağar ad- Durr'. Ainsi, il est clair que la femme a contribué à l'avancement des arts et de l'architecture ce qui laissé des traces remarquables sur la civilisation du Caire islamique.
\end{abstract}

Mots clés: la femme- les arts appliqués- bijouterie- miroir- parfum- maison - ḩānqāh- sabīl- mausolée- caravansérail.

\section{Résumé}

A travers les siècles, la femme avait un impact indéniable dans la société cairote; elle a joué un rôle aussi important que celui de l'homme; en tant que mère et épouse, elle effectuait son enchaînement de tâches familiales et sociales. La contribution de la femme dans la vie publique était incontestable malgré les restrictions sociales imposées par les traditions, comme en témoignent les biographies qui mentionnaient les noms de certaines femmes dont l'activité politique, intellectuelle, religieuse et sociale, a forgé l'histoire du Caire; elles étaient savantes, poètes, narrateurs du hadìths, littéraires et médecins. Les arts appliqués doivent beaucoup de leur prospérité aux doigts qualifiés des femmes cairotes et à leur goût manifesté dans la fabrication de céramique et de poterie.

Elle a également contribué dans le domaine du textile et de tapis dont la variété et l'élégance de ses produits a rendu cette industrie célèbre dans d'autres. De même, la femme cairote a fourni sa part dans l'industrie de la bijouterie et le développement de nouveaux types de parures, ainsi que les produits cosmétiques comme les peignes, les miroirs, les flacons de parfums et les pots de fard. Dans le domaine de l'architecture, la femme avait un grand impact dans la conception de logements, puisque l'architecte visait à protéger la vie privée de la femme, par conséquence, la maison était aménagée d'une cour centrale à ciel ouvert, les fenêtres étaient couvertes par des mašrabiyyas (fenêtre grillagées de bois tourné), encore, une aile séparée y était consacrée (le harem) pour assurer son confort.

En plus des maisons, la femme a également un impact sur l'architecture de certaines institutions religieuses importantes telles que les hānqāhs (maison soufie), les mosquées, les madrasas et les mausolées. Parmi ces femmes était la fameuse "Alam al- Amīriyya' qui a ordonné la construction du mausolée de 'Sayyida Ruaqya' et 'Šağar ad- Durr' qui a fait bâti un mausolée qui persiste encore au Caire, le mausolée de 'Fāṭima Hुātūn' et la madrasa de 'Umm al- Sulțān Ša 'bān'.

Ainsi, il est clair que la femme a contribué à l'avancement des arts et de l'architecture ce qui laissé des traces remarquables sur la civilisation du Caire islamique. 


\section{Introduction}

À travers les siècles, la femme jouissait d'un grand respect et a joué un rôle aussi remarquable que celui de l'homme dans la société Egyptienne. Un de ses rôles était lié à sa propre vie privée dans la maison puisqu'elle gérait les affaires de la première cellule de la société qui est la famille, en plus, était responsable d'inculquer les bonnes mœurs à ses enfants qui seront de bons citoyens. En effet, l'activité et la contribution de la femme à la vie publique était intense, que ce soit son activité politique, intellectuelle, religieuse et sociale, quelques-unes étaient assez renommées dont les noms étaient mémorisés dans l'histoire de l'Egypte. A l'époque Musulmane, les sultans et les princes traitaient leurs mères, leurs épouses et leurs filles avec tant de respect et de vénération; à ce propos, des titres honorifiques leurs étaient attribués, tels que "Hुund"1 "Ȟātūn"2, "Sit al-Qudah" (la dame des juges), "Barakat ad- Dawla" (bénédiction de l’Etat), "Ğalāl an- Nisā’" (l’honneur des femmes), "al- Durra" (la perle), "Salīlat al- Mulūk wa'l Salātīn" (descendante des rois et des sultans), "alMașūna" (la protégée), "al- Ğalīla" (la noble) et "ghusn al- Islām" (branche de l'Islam), même dans les lettres, ces expressions d'irrévérence leurs étaient accordées pour les glorifier et les honorer. ${ }^{3}$ Quant à la femme du peuple, elle jouissait également d'un statut assez honorable, la population comme l'Etat la tenait en haute estime, les meilleurs témoins sont les différents titres pompeux que les gens attribuaient à leurs épouses et leurs filles comme "Sit al- Halq" (la dame de la création), "Sit al-Kul" (la dame de toutes), "Sit al- Nās" (la dame des gens). ${ }^{4}$

La femme, faisant partie d'un haut rang social, comme la caste dominante, était honorée non seulement durant sa vie mais encore après sa mort; Les chroniqueurs rapportent qu'au décès d'une sultane, d'une fille ou d'une favorite du sultan 5 , une cérémonie unique accompagnait son ensevelissement; son cercueil était enveloppé d'une gaze bordée d'or, le sultan, les grands émirs et les principaux fonctionnaires de l'Etat priaient pour la défunte, ils cheminaient devant la bière, et distribuaient des aumônes pénitentielles tout au long du parcours. ${ }^{6}$ Signalons encore que l'Islam honorait la femme, ses législations ont indiqué et éclairci beaucoup de questions qui concernent le statut et le mode de vie de la femme dans la société Musulmane, ces droits appuyaient sur des versets coraniques.

Premièrement, l'égalité avec l'homme:

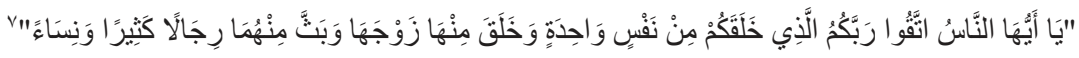

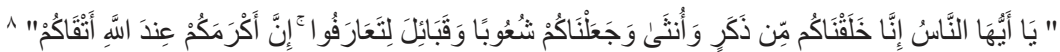

Ensuite, l'indépendance de la responsabilité de la femme de celle de l'homme:

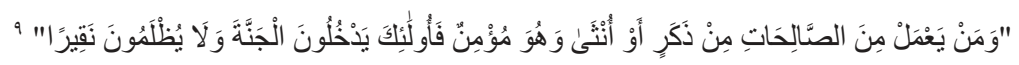

D'ailleurs, même le droit du statut personnel de la femme, tout ce qui concerne le mariage ${ }^{10}$, le divorce, l'héritage.. etc., dérivait de la loi islamique et mis en évidence par le coran qui réservait la dignité de la femme.

\section{Rôle de la femme dans la société musulmane}

Bien que la femme passe la plupart de son temps dans le harem, il était normal qu'elle le quittait pour visiter ses amies, assister à des cérémonies familiales ou religieuses, et malgré les coutumes qui limitaient sa vie, elle aimait se rendre au marché et dans les boutiques, ces sorties étaient considérées une sorte de divertissement, les marchés étaient des centres sociaux ou elle pouvait rencontrer des amis et savoir les nouvelles, ${ }^{11}$ et s'il n'y a rien à acquérir sur les marchés, elle se rendait aux bains publics qui étaient une place d'étalage de richesse et de beauté et un lieu où se rassemblaient les intrigues, les nouvelles et les rendez-vous. ${ }^{12}$

Concernant le travail de la femme, l'Islam n'a jamais interdit à la femme de travailler hors de sa maison, cette tolérance de l'Islam est claire dans le Coran:

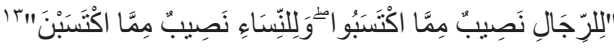

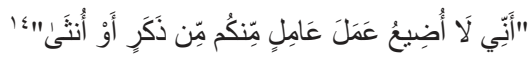

Notant que la femme a maîtrisé plusieurs professions, non seulement comme professeurs et poétesses, mais encore dans des carrières correspondantes à celles des hommes; shayhāt, faqīhāt, d'autres étaient wā' izāt et même sūfīyāt, et bien d'autres occupations indispensables à la vie sociale, ${ }^{15}$ comme marieuses, vendeuses, coiffeuses et chanteuses. ${ }^{16}$ Les historiens, surtout as- Sahāwīe qui a consacré un volume entier dans son ouvre "al- Daw' al- Lāmi " aux biographies des femmes du IX ${ }^{\text {ième }}$ siècle, ont rapporté que plusieurs savants ont consacré leur temps au savoir et à l'éducation de la femme comme c'était le cas d'Abūl 'Abbās Ahmad, Al- Ša 'rān̄̄ a expliqué que la raison était le besoin constant de la femme d'apprendre les obligations de sa religion et les droits de son mari. ${ }^{17}$ 
As- Sahāwī a mentionné les noms de šayhāt qui lui apprenaient le Coran et les hadīths comme "Amna ibnat alŠams" (décédée en 867 H.), "Amat al- Ḩāliq ibnat al- Zin 'Abd al- Laṭîf" (décédée en 833 H.) et "Um Hāni’ ibnat al- Taqī" (décédée en 885 H.). Certaines femmes au Caire ont également adopté le mouvement de soufisme ${ }^{18}$ et y activement participé, elles portaient les mêmes vêtements porté par les soufis des hommes, celles- ci étaient souvent appelées "mutașawifāt", al- Maqrīzī a mentionné qu'elles habitaient les hanqāhs ${ }^{19}$ et les ribāṭ qui se caractérisaient par leur engagement rituel et le maintien des principes éthiques. ${ }^{20}$ Alors, il est incontestable que la femme à cette époque sort du harem pour participer aux réunions scientifiques et religieuses ${ }^{21}$ dans lesquelles, à ces occasions, une place séparée de celle consacrée aux hommes leur était réservée. ${ }^{22}$ Ces renseignements sur le mode de vie de la femme, permettent d'affirmer qu'elle a joué un rôle essentiel, non seulement dans la vie sociale, mais encore dans la vie intellectuelle et religieuse.

A l'égard de son rôle dans la vie politique, les sources abondent en renseignement sur l'influence étendue des femmes, surtout celles qui faisaient partie de la classe dominante dans la société. Parmi ces femmes, était la célèbre "Šağar ad- Durr", la première sultane Mamelouke de l'Egypte, elle avait une personnalité très forte et elle était capable d'administrer les affaires du pays au cours d'une période assez critique après la mort de son époux; le sultan "aṣ- Șāliḥ Nağm ad- Dīn Ayyūb" et lors d'une expédition française conduite par Louis IX, elle a caché la nouvelle du décès du sultan pendant trois mois jusqu'à l'arrivée de son fils "Tūrān Šāh". ${ }^{23}$ Un autre exemple est celui de "Hund", fille de l'émir "Aqbardī al- Dawādār", ${ }^{24}$ et femme du sultan "Țūmān Bāy" qui a fait asile dans la maison du calife abbasside du Caire après l'assassinat de son mari, alors qu'elle a tant souffert des harcèlements des autorités Ottomanes et a perdu une grande partie de sa fortune. ${ }^{25}$ Cette prérogative féminine était ainsi constaté lors de la visite de quelques femmes de la famille Ottomane régnante au Caire, ou même en leur chemin pour le pèlerinage à Mecque, le peuple avait parfois eu recours à ces princesses demandant leur intervention chez le sultan en leur faveur, ceci est parvenu avec la reine "Hātūn", tante du sultan "Sulaymān"; lors de sa visite au Caire, quelques citoyens ont demandé de la voir pour porter plainte contre "Hāyir bek", le préfet d'Egypte qui a ordonné de les envoyer en exil, alors qu'il a révoqué cet édit grâce à son intervention. ${ }^{26} \mathrm{Al}-\mathrm{Maqrīzi}$ nous a fourni un autre exemple de l'an 737 H./ 1336 J.C. quand le sultan "an- Nāṣir Muhammad" a confisqué les biens de quelques commerçants et même l'intervention des émirs était en vain, alors, quand "Sit Hadaq", la femme du sultan a intercédé en leur faveur, le sultan a accepté sa demande. ${ }^{27}$

\section{Impact de la femme sur les arts appliqués}

La femme, ayant un goût incontestable, a joué un rôle signifiant dans le progrès des arts appliqués, elle a contribué à l'industrie du textile et à la création d'une variété de produits d'une excellente qualité qui témoignait de sa dignité et la rendait célèbre dans d'autres pays. L'invention de la mode et la réalisation des costumes étaient la responsabilité de la femme, ainsi que la fabrication et le développement de divers textiles, elle faisait de belles broderies, elle utilisait une variété de tissus de soie et de laine, parés d'or, d'argent, et parsemé de pierres précieuses. Parmi les fabrications importantes étaient la soierie, (fig.1) le brocart et le fin lin qui étaient utilisés dans l'industrie des mantilles et des draps.

Il était fréquent que les femmes brodent les tissus, les manches minces, les capuchons, les nattes, les écharpes, les serviettes, les oreillers et les chaussettes, qui ont été faites de soie, de laine ou de cuir, ainsi que des pantoufles, parfois, ces produits étaient ornés de bijoux. Les vêtements portaient de nombreux motifs de décoration, comme on en voit un exemple sur un fragment de soie, datant de l'époque Fatimide, orné de médaillons contenant des motifs de plantes, d'animaux et des bandeaux épigraphiques. L'élément ornemental le plus important est une bande de médaillons ovales contenant des canards et des lapins stylisés alternés sur un fond de motifs floraux simples. ${ }^{28}$

La contribution de la femme à cette industrie ne se limitait pas à la production et à la création de nouvelles lignes de mode, parfois, elle était la propriétaire d'usine de textile ${ }^{29}$ comme l'indique le document waqf de "' $\bar{A}$ 'iša ibnat almarhūm as- Sayyid Fitih al- Ğāwī̌s" qui l'a acheté de sa fille "Zamzam". ${ }^{30}$ Certaines femmes ont éventuellement influencé l'évolution des vêtements féminins à cette époque, comme "Zubaydah" femme d'"al- Rašīd" et mère d'"al- Amīn", qui a introduit des modifications aux habits comme l'utilisation des écharpes et des pantoufles ornés de bijoux, en plus, elle est allée parfois trop loin dans l'achat et la décoration de ses vêtements à un tel point qu'elle a ordonné de lui faire une robe en broderies dont le prix a dépassé cinquante mille dinars. ${ }^{31}$

Evidemment, la mode a subi tant de changement à travers l'époque Musulmane; parmi les pièces qui étaient largement en usage aux époques Mameloukes et Ottomanes; al- qamīṣ, ${ }^{32}$ al- zinār, ${ }^{33}$ al- 'ușāba, ${ }^{34}$ et al- burqu ' ${ }^{35}$ Concernant les bijoux, la femme exagérait dans l'acquisition et le développement de belles parures avec des ornements minutieux, elle aimait porter les bracelets de cheville (hulhāā) dorés, les colliers ('uqd) parés des pierres les plus précieuses. ${ }^{36}$ Préalablement, il paraît que l'utilisation des colliers était une formule simple pour porter un objet de la nature, on estimait qu'elle possède des forces magiques qui protègent des malheurs et de mauvaises âmes. ${ }^{37} \mathrm{Il}$ en existait plusieurs modèles, les femmes riches portaient des colliers assez précieux parfois assortis de pièces de monnaie en or pur, tandis que femmes issues des couches sociales moins favorisés portaient des colliers en argent, en cuivre émaillé ou en perles creuses appelées 'libba' ${ }^{38}$ 
En outre, des pendentifs de diverses formes étaient en usage, surtout ceux fabriqués en ambre ${ }^{39}$, très répandus à l'époque Mamelouke comme le mentionnait 'Al- Maqrīzì' "En Egypte, presque toutes les femmes même les infortunées, possédaient des pendentifs en ambre". ${ }^{40}$ On trouve un exemple de ces colliers en or, composé de trois pendentifs ronds décorés de fils entrelacés en forme de boutons, le pendentif situé au centre est accroché à un croissant inversé gravé d'émail coloré sur lequel on peut lire: «Gloire éternelle», au milieu duquel se trouve un rubis rouge. (fig. 2) De même, elle portait les bracelets (damālĭğ), les boucles d'oreilles (aqrāṭ) (fig. 3) et les bagues (hātim) (fig. 4) caractérisées par une décoration très élaborée comme les fils de dentelle ornés à leur tour de pierres précieuses dont les plus utilisées étaient les perles, le rubis qu'on appelait «al- bahramānī»»1, les saphirs bleus et jaunes, les émeraudes, les diamants et la turquoise, d'ailleurs, une des méthodes utilisées pour la décoration des bijoux était l'émail.

Il était fréquent qu'on porte des bagues dont le nom y était engravé; c'était un substitut de la signature, une coutume pratiquée particulièrement par les hommes et partagée par les femmes des hauts rangs sociaux. ${ }^{42}$ En effet, il était normal que ces parures précieuses soient particulièrement gardées contre le vol, ainsi, des boîtes spéciales étaient ouvragées pour ce but, on utilisait des matériels d'une grande valeur pour les fabriquer, comme l'ivoire et l'ébène nacré, ces caisses étaient appelés « ̌̌akmağiyya». (fig. 5) Cette pièce appartenait, en particulier, à la dame de la maison, personne n'est permet d'y toucher, toujours gardée au harem «haramlik», dans une place où les visiteurs n'accédaient pas. D'habitude, alšakmağiyya est laissée ouverte sur une table de même type, elle était souvent de forme rectangulaire, à cinq faces, sa porte est y reliée par deux joints, sur la partie supérieure de la porte se trouve un petit cadenas pour le fermer à serrure si l'on a besoin. ${ }^{43}$

Il est valable de noter ici que les califes musulmans accordaient beaucoup d'intérêt à la sécurité du peuple et la tranquillité de sa vie, c'était pour cette raison que l'Etat a établi «dār al- 'iyar» pour contrôler le commerce des bijoux, en outre, on a consacré un budget à cette maison de sorte que les cymbales et les balances n'étaient gère vendues qu'à travers cette maison. ${ }^{44}$ D'ailleurs, l'apport de la femme dans l'industrie cosmétique est indisputable, l'importance qu'elle accordait à ses produits de beauté reflète l'intérêt à son bien-être et à son apparence. ${ }^{45}$ Les produits cosmétiques se sont bien développé à l'époque musulmane surtout sous les mameloukes dont les traces sont innombrables; tels que les peignes, les miroirs, les fards et les parfums.

Les peignes étaient fabriqués de bois, qui était la matière la plus en usage, d'ivoire et d'ébène ${ }^{46}$ et dont la partie médiane était décorée avec une peinture, ou en relief par une variété de formes géométriques, florales, animales, des oiseaux, des poissons et parfois la décoration était élaborer par des bandeaux épigraphiques comprenant des phrases significatifs et qui ne manquent pas d'humour parfois. Le Musée d'Art Islamique contient maints d'exemples sur les peignes, l'un d'eux est en bois, à dents fines, datent de l'époque Toulounide, celui- ci est orné dans sa partie médiane d'un relief composé de l'alternance de têtes d'oiseaux dont les becs se touchent, ces têtes sont séparées par des ornementations géométriques sous forme de losanges ainsi que des fleurs. ${ }^{47}$ (Fig. 6)

Les miroirs étaient un des produits de beauté les plus valable chez la femme, fabriqué de cuivre, bronze, d'argent et d'or, parfois, il était à double facette, l'un poli et reflète l'image du visage, l'autre garni de divers motifs; humains, animaux, floraux et géométriques ou bien des motifs épigraphiques coufique et naskhi. Un exemple est fourni par la collection des miroirs au Musée d'Art Islamique: miroir en cuivre, rond et doté d'une poignée comprenant de nombreux côtés avec des lignes séparées légèrement gravées, le dos comporte un cercle central orné de plantes, autour du cercle, une prière est inscrite en calligraphie naskhi dans quatre ovales qui sont séparés par des cercles contenant chacun une fleur de lotus. L’inscription comprend les phrases suivantes: "Victoire, attrait et bénédiction," "Bonté, gloire, grâce et générosité," "La tolérance et la connaissance sont des ressources," "Votre statut est si suprême que les Arabes et les non-Arabes sont incapables de vous accorder l'entière reconnaissance qui vous revient." (fig. 7)

$$
\text { "العز و النصر و الإقبال و النعم"، "و الخير و المجد والأفضال و الكرم"، "و الحلم والعلم أسباب علوتها"، "فحار فى وصفلك الأعراب و العجم". }
$$

En Outre, l'utilisation de ces miroirs métalliques se référait, parfois, à la magie, des inscriptions gravées servaient éventuellement à cet objectif, ${ }^{48}$ un exemple est un miroir en bronze conservé au Musée d'Art Islamique, il est entouré par sept cercles, à l'intérieur desquels est représenté le zodiaque et on lit l'inscription suivante: "au nom de Dieu le Miséricordieux, ce miroir béni a été fait dans un bon jour, il est utile - si Dieu le permet- pour la fidélité, les femmes divorcées et pour toutes les douleurs, fait en l'an 548, louanges au Dieu seul, la paix et la reconnaissance au Prophète Muhammad et sa famille, réalisé au passage du soleil sur le signe du bélier avec sept métaux." 49

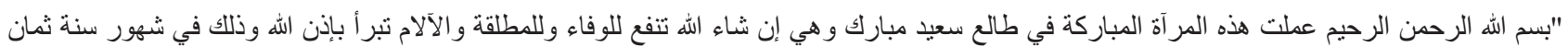

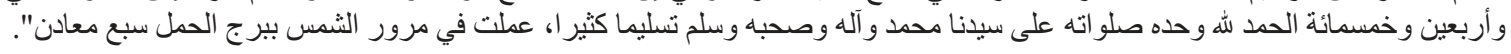

Parmi les accessoires cosmétiques indispensable pour chaque femme était les bouteilles de fard, elle accordait une importance considérable au maquillage des yeux, et un soin particulier aux sourcils, elle tenait beaucoup à leurs forme pour qu'ils soient soit arqués comme dessinés au pinceau, soit épais avec des contours nets, cela indique l'importance de la cire 
pigmentée et le fard qui étaient des produits d'esthétique essentiels. La bouteille à fard, fabriquée parfois d'or incrusté de pierres précieuses ou d'argent, était dotée d'un stylet, une fois verrouillée, il se tient à l'intérieur de la bouteille, ensuite, le stylet était trempé avant de sortir la poudre du fard. On aperçoit tant de modèles de stylet dont le capot supérieur a été réalisé sous diverses formes ornementales; un oiseau ou un animal, ce stylet ressemblait souvent à certains outils médicaux de la chirurgie, et à cause de son utilisation dans l'œil, il était toujours fabriqué par des techniciens experts. ${ }^{50}$ Un bel exemple, conservé au Musée de l'Art Islamique, remontant à l'époque Mamelouke présente une bouteille de fard en ivoire incrustée d'or, de forme hexagone tenue sur une base formée de six plumes, son stylet est y attaché par une courte chaîne. (Fig. 8)

Un autre exemple de récipient de fard et un stylet, datant de l'époque Ottomane, fabriqué en argent, doté d'un corps en forme de poire, qui se rétrécit vers le haut pour se terminer par un bec circulaire, le corps est orné d'un groupe de cercles délimité par des lignes dépassant du haut et du bas, son stylet se termine par la représentation d'un coq abstrait. ${ }^{51}$ (Fig. 9) La parfumerie était une industrie bien réussie en Egypte de sorte que quelques types ont été fabriqués en utilisant de seize essences, les essences ont été utilisées pour imprégner les maisons, en plus, elles ont été semées pendant les fêtes de mariage. ${ }^{52}$ Non seulement le musque et l'ambre étaient des parfums favorites pour la femme, mais encore ceux extraits des fleurs, des feuilles, des fruits, des pelures et des graines. La femme aimait tant les parfums, elle a utilisé différents sortes de flacons faits de verre, de cristal de roche, de porcelaine et de cuivre incrusté d'or et d'argent, le verre était également utilisé dans sa fabrication, parfois émaillé, incisé ou chanfreiné. De même, la décoration de ces récipients était florale, animale ou épigraphique. ${ }^{53} \mathrm{Un}$ exemple unique de ces flacons remonte à l'époque Ottomane, fabriqué en argent, le corps ovale dont la base ressemble à un feuillage assemblé composé de bordures florales, le couvercle est un long tronc composé de branches d'arbre avec des feuilles et des fleurs tombantes et couvrant la partie supérieure du flacon. (fig. 10)

\section{Impact de la femme sur l'architecture Islamique du Caire}

Dans le domaine de l'architecture civile, l'impact de la femme était significatif. La protection de la femme des yeux des étrangers a été l'un des facteurs les plus importants qui ont influencé la conception de l'architecture domestique; les façades ne comprenaient pas des fenêtres à proximité des passants ou même des chameliers; elles étaient exécutées le plus haut possible. Ensuite, les ouvertures des fenêtres étaient également bloquées par des belles «mašrabiyya» en bois tourné en saillie, qui permet à ceux qui sont à l'intérieur de la maison de voir la rue et les passants sans être vus de l'extérieur, ${ }^{54}$ de même, l'entrée de la maison a été aménagée de sorte qu'elle ne s'ouvrait pas directement à l'intérieur; elle amène dans un couloir en chicane, qui aboutit à la cour centrale, encore, il existait des entrées secondaires privées, alors que les visiteurs ne peuvent pas voir les femmes en entrant à la maison. ${ }^{55}$ D'autre part, l'intérieur de la maison se composait de deux parties, l'une au rez- de- chaussée consacrée aux hommes qu'on appelait (salāmlik), cet étage était préparé et destiné à la réception des visiteurs et aux concerts, en plus, il était doté d'une salle qu'on appelait «qā 'a» ou «mandara» qui servait à ce but. L'étage supérieur, était spécialement consacré aux femmes (haramlik), et destiné à assurer leur isolement.

D’ailleurs, les $\bar{l} w a \bar{n} n s$ étaient fournis par des pièces en pierre appelées «șuffa»qui servaient à mettre les flacons de parfums, les accessoires cosmétiques et les tasses. ${ }^{56}$ Afin d'assurer une atmosphère confortable à l'intérieur de la maison, la cour - que ce soit à ciel ouvert ou pas- était parfois dotée d'une fontaine, et un salsabīl. ${ }^{57}$ Quelques maisons avaient un jardin avec de diverses plantes et fleurs. De même, des cheminées d'aération «malqafs» ${ }^{58}$ ont été aménagés pour garantir une bonne aération à l'intérieur de la maison. ${ }^{59} \mathrm{Il}$ existe encore des beaux exemples de l'architecture domestique fondée pour les femmes au Caire comme: la maison de «Sit Wasīla» ${ }^{60}$ et la maison de «'Amna bint Sālim». ${ }^{61} \mathrm{La}$ femme a également laissé ses empreintes sur un autre type assez important de l'architecture civile qui est le sabīl ${ }^{62}$ (fontaine publique), comme sabīl «al- Sit Șāliḥa», ${ }^{63}$ sabīl «Ruqayya Dūdū» ${ }^{64}$ (P1. 1) et sabīl «Nafīsa al- Baydā», ${ }^{65}$ qui remontent à l'époque Ottomane.

D'emblée, l'impact de la femme s'est étendue sur la vie économique du Caire, elle a fait fonder des caravansérails «Wikāla», ${ }^{66}$ qui étaient répandus au Caire dès l'époque Fatimide, mais, ont atteint leur apogée aux époques Mameloukes et Ottomanes. La richesse de la femme était bien constante à cette époque puisqu'elle était la propriétaire de caravansérail qui constituait une source de richesse et un signe de prestige et d'autorité. Parmi les exemples de caravansérails possédés par des femmes à l'époque ottomane, était «wikālat Nafisa al-Bayḍ $a .{ }^{67}$ Le caravansérail a été bâti sur un vaste terrain, ce qui implique la position sociale favorite dont jouissait la propriétaire, fondé entre bāb Zuwayla et la mosquée d'al- Mu'ayid, il n'en reste aujourd'hui que la grande façade qui donne sur la rue d'al- Mu'iz, l'entrée est située au milieu de cette façade. Cette entrée donne accès à un corridor dihlīz rectangulaire voûté qui aboutissait autrefois à la cour du caravansérail, autour de laquelle ont été aménagées les dépendances. ${ }^{68}$ (Pl. 2) En outre, la femme a laissé ses traces sur l'architecture religieuse, comme les mosquées, les collèges et les mausolées. A l'époque Fatimide, remontent des exemples de la contribution de la femme comme la reine «Taghrīd», femme du calife al- Mu'iz et mère d'al- 'Azīz, qui a fait fonder un palais et une mosquée à $a l$ - Qarāfa au sud du Caire; en plus d'une manzara au bord du Nil avec un bain «hamām» connu sous le nom de «hamām al- dahab». ${ }^{69} \mathrm{Un}$ autre exemple est celui de «Alam al- Amiriyya» qui a fait fonder le mausolée de «Sayyida Ruqaya», encore, «Šağar al- Dur» qui a fait édifier deux mausolées qui persistent encore au Caire, l’un pour son mari «as- Șāliḥ Nağm 
ed- Dīn Ayūb» à Nahassin près de l'īwān Ouest du collège as- Șaliḥiyya, et l'autre pour elle dans la rue al- Khalifa près de la mausolée du «Sayyida Ruqaya». 70

\section{Conclusion}

De ce qui précède, on peut déduire les points suivants:

- La femme était vénérée à l'époque Islamique, tant de titres honorifiques y ont été attribués comme "Hātūn", "Barakat ad- Dawla", "Ğalāl an- Nisā’", "al- Durra", "Salīlat al- Mulūk wa’l Salātīn", "al- Mașūna", "ghusn alIslām","Sit al- Halq", "Sit al-Kul", "Sit al- Nās", ce respect était accordé à la femme du haut rang social ainsi que la femme du peuple.

- Une des coutumes qui implique l'autorité et l'influence qu'avaient les femmes à cette époque était leur intervention chez les sultans en faveur de citoyens.

- Tout au long de l'époque Musulmane, la femme a maîtrisé plusieurs professions indispensables à la vie sociale, comme marieuse, vendeuse, coiffeuse et chanteuse, ainsi que des carrières correspondantes à celles de l'homme; elle était šayhā, faq̄īā, wā' izā et șūfìyā, il y a même des femmes qui ont fait fonder des hānqāhs comme «Tughāy Um Anūk», femme du sultan an- Nāṣir.

- Dans le domaine des arts appliqués, la femme avait des traces marquantes surtout dans l'industrie des produits de beauté comme les peignes, les miroirs, les parfums et le fard.

- Sur le plan économique, la femme jouissait d'un statut considérable, elle possédait des usines de textiles comme c'était le cas de «' $\bar{A}$ 'iša ibnat al- marḥūm as- Sayyid Fitị̣ al- Ğāwī̌š, ainsi, sa contribution dans la production des textiles et l'invention de nouvelles lignes de mode est indisputable.

- Sur le plan architecturel, elle avait un impact significatif que ce soit dans la conception de la construction des maisons, basée sur sa protection et son confort, ou sa contribution, en tant que propriétaire, dans la construction de diverses fondations civiles, religieuses et commerciales.

Endnotes:

1. Hund: (pl. hundāt) un mot perse qui était largement en usage dans le monde musulman, il signifiait la dame ou la princesse, à l'époque Mamelouke il était spécialement attribué aux femmes des sultans.

- Al- Qalqašndī, Šihāb ad-Dīn Abū Al- 'Abbās Aḥmad (d. 821 H.); Șubḥ al- A '̌sāa, (14 vols), Būlāq, le Caire, 1915, vol. 6, p. 78.

- 'Āšūr, S., Al- Mugtama' al- Mașrī fi 'aṣr Salāṭịn al- Mamālīk, Dār al- Nahḍa al- 'arabiyya, le Caire, 1992, p. 143.

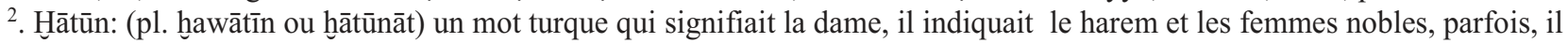
était relié au nom de la femme comme "Daifa hāāūn", la fille du roi al- 'Ādil et la femme du roi az- Zāhir Ghāzī.

- Al- Bāšāă, Ḥ., al- Alqāb al- Islāmiyyafi al- Tārīh wa'l Wathā’iq wa'l Athār, dār al- Nahḍā al- 'Arabiyya, 1978, p. 264- 266.

- Al- Qalqašandī, Șubḥ al- A'šā, vol. 7, p. 166.

3. Ibn Al- Ḥāğ, Abū 'Abdullah Muḥammad ibn Muḥammad al- 'Abdarī al- Fāsī (d. 737 H.); Al- Madhal, le Caire, 1929, vol. 1, p. 238.

- 'Abd al -Rāziq, A., al- Mar’a fi Mașr al- Mamlūkiyya, al- Hay’a al- Mașriyya al- 'Āmma lil Kitāb, le Caire, 1999, p. 16.

4. 'Āšūr, S., Ibid, p. 145.

5. Quelques favorites avaient une influence intense sur les sultans, les sources fournissent tant d'exemples sur le pouvoir qu'elles exerçaient du fait que les sultans étaient obsessionnellement amoureux d'elles; elles jouissaient d'un prestige et d'une puissance de sorte qu'elles étaient parfois autoritaires.

- 'Abd Al- Nabīi, H., Al- Zawāğ fi usar Salāṭ̄n al- Mamālīk, AnIsl 42, 2008, p. 31.

${ }^{6}$. As- Sahāāī, Šams ad- Dīn Muḥammad ibn 'Abdul Raḥmān (d. 902 H.), al- Du' al- Lāmi' li Ahl al- Qarn al- Tāsi, Maktabit al- Quds, (12 vols), 1354 H, vol. 12, p. 114.

- Ibn Iyās, Muḥammad ibn Aḥmad al- Ḥanafì (d. 930 H.), Badā'i' al- Zuhūr fi Waqā’'i al- Duhūr, le Caire, 1982, vol. 2, p. 214.

7. Coran.; surat al- Nisā̄, verset 1 .

${ }^{8}$. Coran.; surat al- hugurat, verset 13 .

9. Coran.; surat al- Nisā', verset 124 .

10. Les contrats de mariage de l'époque Islamique mettent en évidence le statut de la femme, les dots qui lui étaient présentés, son droit de se divorcer et d'autres aspects de la vie sociale de l'époque.

Voir :- 'Abd al- Rāziq, A., 'Aqdā Nikāḥ min 'Așr al- Mamālīk al- Baḥariyya, al- Mağala al- 'Arabiyya lil 'Ulūm alInsāniyya, n 22, vol. 6, Kuwait, 1986. 
11. 'Āšūr, S., Al- Mugtama' al- Mașrīî, p. 154- 155.

12. 'Abd al -Rāziq, A., al- Mar'a fi Mașr al- Mamlūkiyya, p. 46- 47.

13 . Coran, IV/32.

${ }^{14}$. Coran, III/195.

15. Ibn Hağar al- 'Asqalānī, Šehāb ad- Dīn Aḥmad Ibn 'Alī Muḥammad (d. 852 H.), Anbā' al- Ghamr, le Caire, 1969, vol. 2 , p. 841.

16. Abd al- Rāziq, A., La Femme aux Temps des Mameloukes, p. 37-38.

17. As- Sahāwī, al- Du’ al- Lāmi', vol. 2, p. 111.

18. Durant l'époque Mamelouke, le mysticisme était fort en vogue; certaines femmes cairotes le professeraient.

Voir:- 'Āšūr, S., Al- Mugtama' al- Mașrī, p. 179- 194.

19. Il y a des exemples de femmes qui ont fait fonder des hāanqāhs comme «Tughāy Um Anūk», femme du sultan an- Nāșir qui a ordonné la fondation d'une hāanqāh soufie et un mausolée pour elle -même en dehors de bāb al- Barqiyya au Caire.

- Al- Maqrīzī, Taqī ad- Dīn Aḥmad (d. 854 H.), al- Mawa 'iz wa'l I'tibār bi Zikr al- Huiṭat wa'l Āthār, Būlāq, 1270 H., vol. 2 , p. 426.

- Sur les fondations pieuses fondées par des femmes à l'époque Isl amique, voir: Abū al- Mağd, Z., Awqāf al- nisā', dans: Al- Mar'ā wa'1 Ḥậāra, vol.1, 2000, p. 20-28.

20. Al- Maqrīzīi, al- Hițat, vol. 2, p. 294.

21. Jusqu'au $X V^{\text {ème }}$ siècle, la femme déplaçait librement dans les rues, c'était sous les Ottomans que la circulation des femmes a été restreinte pour éviter les affrontements avec leurs troupes. C'était durant leur règne que la réclusion féminine apparaît assez clairement.

- Garcin J. C.; Maury B.; Revault J.; Zakariya M., Palais et maisons du Caire, T I, époque mamelouke, Paris, 1982, p. 213.

22. Ibn Al- Haāğ, Al- Madhal, vol. 2, p. 219.

23. Berchem, V. M., Matériaux pour un Coprus Inscriptionum Arabicarum, Paris, 1903, vol. 1, p. 372.

- Fahmī, A.; Al- Qāhira Tarihhha Funūniha ĀThariha, Mațābi` al- Ahram al- Tugariyya, le Caire, 1970, p. 190.

24. Al- Dawādār est un titre qui signifie celui qui porte l'encrier; son rôle était de diffuser les lettres du sultan et de porter les plaintes du peuple au sultan.

- Al- Qalqašandī, Șubḥ al- A‘šā, vol. 5, p. 461.

25. Ibn Iyās, Badā'i ' az- Zuhūr, vol. 5, p. 181- 182.

26. Ibid., Vol. 5, p. 404- 405.

27. 'Ašūr, S., Nisā' al- Qāhira fi 'Așr al- Mamālīk, al- Nadwa al- Dawliyya li Tārīh al- Qāhira, Mars- Avril 1969, p. 570.

28 . À l'époque Fatimide, les motifs décoratifs contenant des êtres vivants étaient forts en vogue.

29. À l'époque Ottoman, ces usines de textiles étaient appelées "Q̄̄̄a hạiyāka' (salle de tissage).

30. Waqf “'Á iša ibnat al- marhūm as- Sayyid Fitih al- Ğāwī̌s", rédigé au mois de Ša bān 1040 H., n 49, Archives du Ministère de Waqfs, lignes 14-15.

31. Ḥamdī, A., Mu idāt al- Tağmīl bi Matḥaf al- Fan al- Islāmī, Dār al- Kutub al- Mașriyya, le Caire, 1959, p. 18- 19.

32. Une large et fine tunique à longues manches de gaze transparente, brodée parfois de fils d'or.

${ }^{33}$. Une ceinture portée autour de la robe que la femme porte sur la tunique (al- qamīṣ).

- 'Abd al- Rāziq, A., Al- Mar’a fi Mașr al- Mamlūkiyya, p. 176- 179.

${ }^{34}$. Un foulard à rayures utilisé pour recouvrir les cheveux, parfois appelé (maqna'a) ou bien (mandīl).

- 'Āšūr, S., Al- Mugtama' al- Mașrī, p. 240.

35. Une pièce d'étoffe qui voile le bas de visage, au - dessous des yeux, par un fin mouchoir de gaze.

- Ibid., p. 240.

- Pour plus d'informations sur les vêtements de la femme, voir: Al- Mașrī, A., Azyā'al- Nisā' fĩ Miṣr min al- Fatḥ al'Uthmānī ḥatta 'Așr Muhammad 'Alī, Thèse de Magistère, Faculté d'Archéologie, Université du Caire, 1988.

36. Al- Bāshā, He., Athar al- Mar'ā fi Funūn al- Qāhira, dans «Al- Qāhira Tārīḩaha Funūnha Qthārha», Mu’assassat alAhram, al- Qāhira, p. 172.

37. Zayn al- 'Ābidīn, A., al- Mașāgh al- Ša ' bī fi Mașr, al- Hay’a al- 'Āmma lil Kitāb, 1981, p. 139.

${ }^{38}$. 'Iliwa, Ḥ., al- Ḥuliy, dans «Al- Qāhira Tārīhaha Funūnha Qthārha», Mu’assassat al- Ahram, al- Qāhira, p. 575.

${ }^{39}$. Il existait un marché d'ambre «sūq al- 'anbariyyīn» à l'époque mamelouke, construit à la place d'une prison de l'époque fatimide sous l'ordre de Qalāwūn.

- Al- Maqrīzī, Al- Hițaț, vol. 2, p. 102.

${ }^{40}$. Ibid., vol. 2, p. $102-103$.

41 . Un genre de rubis à la couleur rouge comme les grenades.

- Al- Akfānī, Muḥammad ibn Ibrāhīm (d. 1348 J.C.), Nuhab al- Zaḩā’ ir fi Aḥwāl al- Gawāhir, Manuscrit, Bibliothèque du Congrès.

42. Al- Mașrī, Ā., Azyā' al- Nisā', p. 157. 
43. Hamdī, A., Mu idāt al- Tağmīl, p. 127.

44. Al- Brāwī, R., Hāâlat Mașr al- Iqtiṣādiyya fi 'Ahd al- Fāṭimyyīn, Maktabat al- Nahụa al- Maṣriyya, 1948, p. 277.

45. Hamdī, A., Mu idāt al- Tağmīl, p. 8.

46. À l'époque Musulmane, les peignes étaient abondants, les femmes en achetaient beaucoup ce qui a incité les ouvriers de les fabriquer minutieusement et de grandes quantités; un marché spécial y été consacré, «sūq al- amšāțiyyīn». ALMaqrīzī a mentionné que"Entre al- madrasa al- șâlihịyya et le sūq des bijoutiers, il y avait tout un marché dont les boutiques ne vendaient que des peignes, on l'appelait «sūq al- amšātịyyīn».

- Al- Maqrīzī, Al- Hițat, vol. 2, p. 97.

47. Siyūr, S., al- Amšāṭ fi Maṣr al- Islāmiyya, Thèse de Magistère, Faculté d'Archéologie, Université du Caire, 2006, p. 101111.

Pour une analyse sur les décorations des peignes voir: 'Abd al- Rāziq, A., Les peignes égyptiens dans l'art de l'Islam Dans: Syria, T. 49, fascicule 3-4, 1972. p. 399-412.

48 . Hamdī, A., Mu 'idāt al- Tağmīl, p. 69.

- 'Abd al- Rāziq, A., Al- Mar’a fi Mașr al- Mamlūkiyya, p. 161- 163.

49. Miḥriz, G., al- Marāyā al- Ma daniyya al- Islāmiyya, Magalat Kuliyat al- Ādāb, vol. 15, Part 1, Mai 1953, p. $130-131$.

50. Lucas, A., Ancient Egyptians Materials and Industries, Cairo, 1945, p. 139.

${ }^{51}$. Al- Mașrī, Ā., Azyā'al- Nisā', p. 170- 172.

52 . Ibid., p. 174.

53. Mitz, A., Al- Haḍāra al- Islāmiyya fi al- Qarn al- Rābi` al- Hiğrī, le Caire, 1940, vol. 2, p. 205.

${ }^{54}$. Ces "mašrabiyya" donnent sur la rue pour assurer air et lumière.

55 . Gayet A., l'Art arabe, Paris, 1893, p. 294.

56. Pauty, E., Les palais et les maisons d'époque musulmane au Caire, le Caire, 1932, p. 51 - 52.

57. Un élément décoratif qu'on trouve souvent à l'intérieur des maisons musulmanes; il était sous la forme d'une plaque en marbre avec des lignes courbes sur lesquelles coulent l'eau, utilisé pour adoucir la chaleur dans la qā'a.

58. C'était une installation composée d'une cheminée, munie parfois à son sommet d'un auvent orienté face aux vents dominants, chargée de capter le courant d'air à l'intérieur de la pièce.

- Aurenche, O.; Callot, O., Dictionnaire Illustré Multilingue de l'Architecture du Proche Orient, Maison de l'Orient et de la Méditerranée, Lyon, 1977, p. 12.

${ }^{59}$. Lézine A., La protection contre la chaleur dans l'architecture musulmane égyptienne, dans: BEO, T. XXIV, Damas, 1971, p. 12.

${ }^{60}$. Monument $\mathrm{n}^{\circ} 445$.

${ }^{61}$. Monument $\mathrm{n}^{\circ} 559$.

62. Un type de fondation pieuse qui joue le rôle d'un réservoir d'eau mis à la disposition de tout le monde dans la cité, parfois édifiée pour commémorer une personne.

- Al- Husaynī, M., Al- Asbila al- 'Uthmāniyya bi Madinet al- Qāhira (1517- 1798), Maktabit Madbūlī, 1999, p. 9.

63. Monument $\mathrm{n}^{\circ} 313$.

64. Monument $\mathrm{n}^{\circ} 337$.

65. Monument $\mathrm{n}^{\circ} 358$

66. Un type de fondation commerciale connu, au début de l'époque Islamique, sous le nom de «hān», de même, son nom «wikāla» est l'abréviation de «Dār al- wikāla» ce qui veut dire «maison des adjoints des commerçants», elle remplissait les fonctions de la bourse de nos jours.

- Yihyyā, S., 'Amā’ir al- Mar'ā fi Mișr fi al- 'Așr al- 'Uthmānī, thèse de Doctorat, Faculté d'Archéologie, Université du Caire, 1988, p. 418-419.

67. Monument $\mathrm{n}^{\circ} 395$.

68. Yihyā, S., 'Amā' ir al- Mar'à, p. 445-448.

${ }^{69}$. Al- Maqrīzī, Al- Hițaț, vol. 2, p. 429.

70 . Ibid., p. 374.

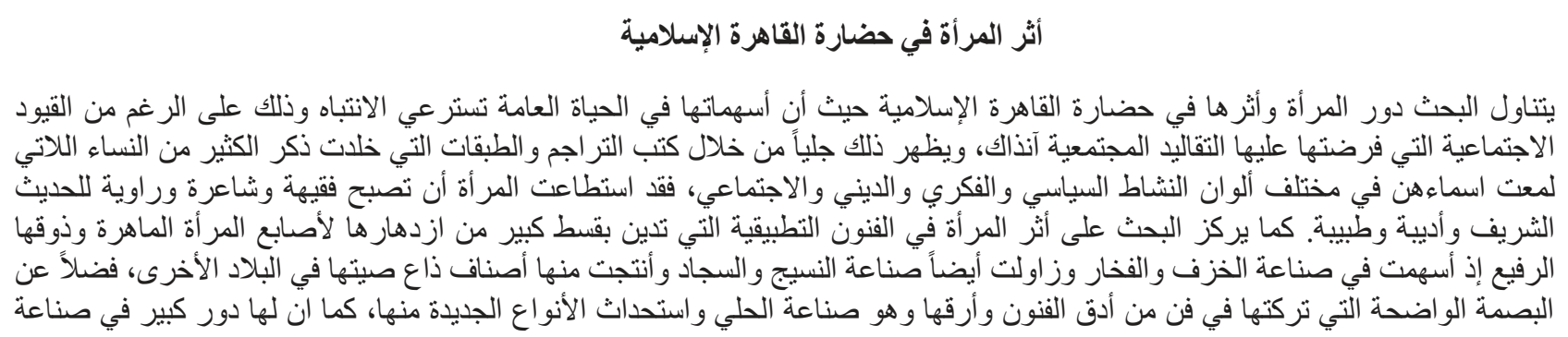




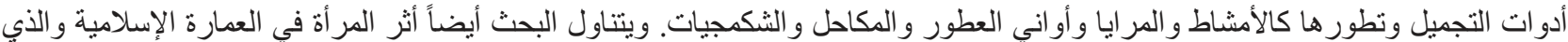

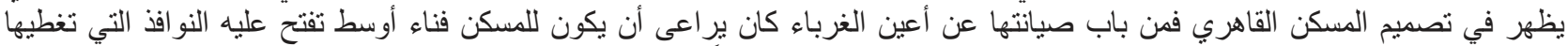

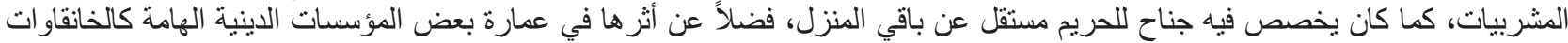

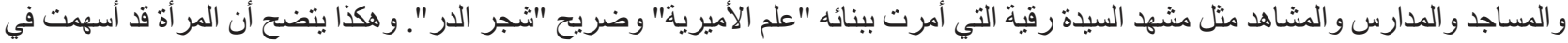
رقي الفنون والعمارة وتركت بصمة واضحة في حضارة القاهرة الإسلامية.

الكلمات الدالة:- المر أة، الفنون التطبيقية، أدو ات التجميل، الحلي، المر ايا، العطور، المنزل، الضريح، السبيل، الوكالة.

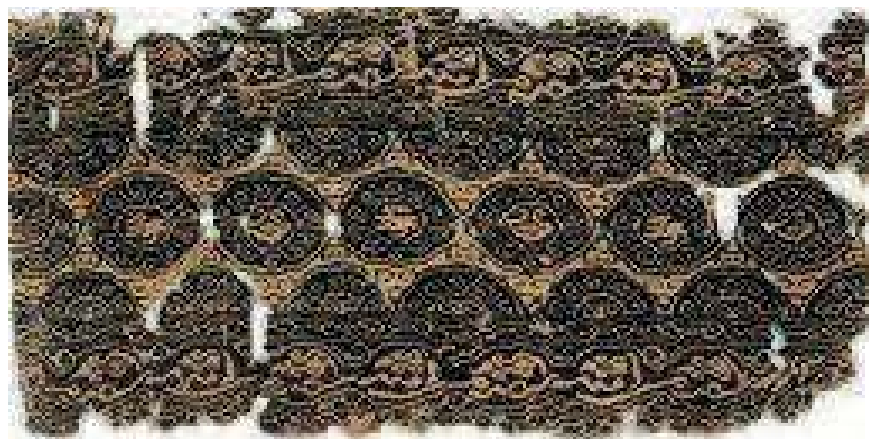

Fig. 1- Un fragment de soie à décors floraux, animales épigraphique - époque Fatimide (5-6 H./ 11-12 J.C.) Musée de l'art Islamique

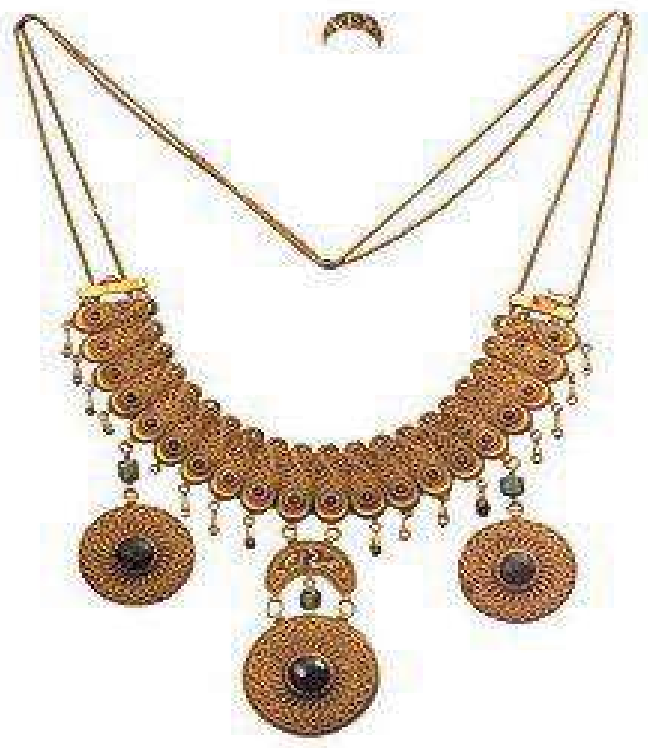

Fig. 2- Collier en or décoré de trois pendentifs - époque Mamelouke (7 H./ 13 J.C.) Musée de l'art Islamique $\mathrm{n}^{\circ} 13749$ 

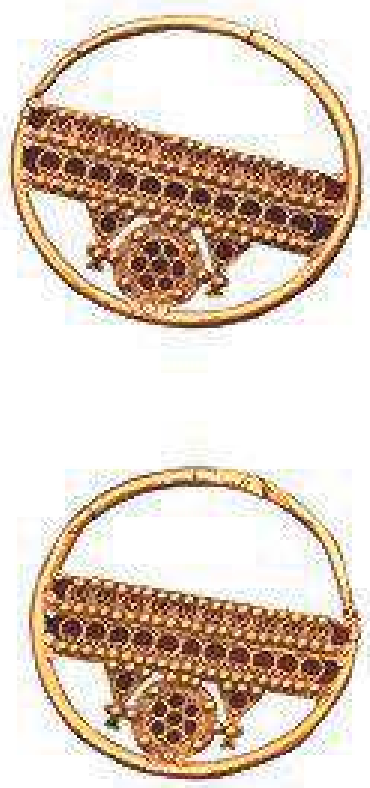

Fig. 3- Boucles d'oreilles ornés de deux pendentifs - époque Mamelouke (8 H./ 14 J.C.) Musée de l'art Islamique ${ }^{\circ} 14991$

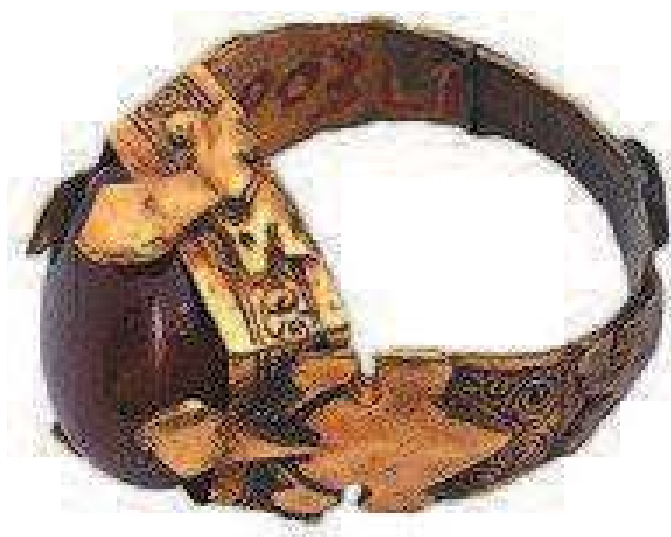

Fig. 4- Une bague en or assortie d'un rubis rouge - époque Fatimide (5 H./ 11 J.C.) Musée de l'art Islamique ${ }^{\circ} 16455$ 


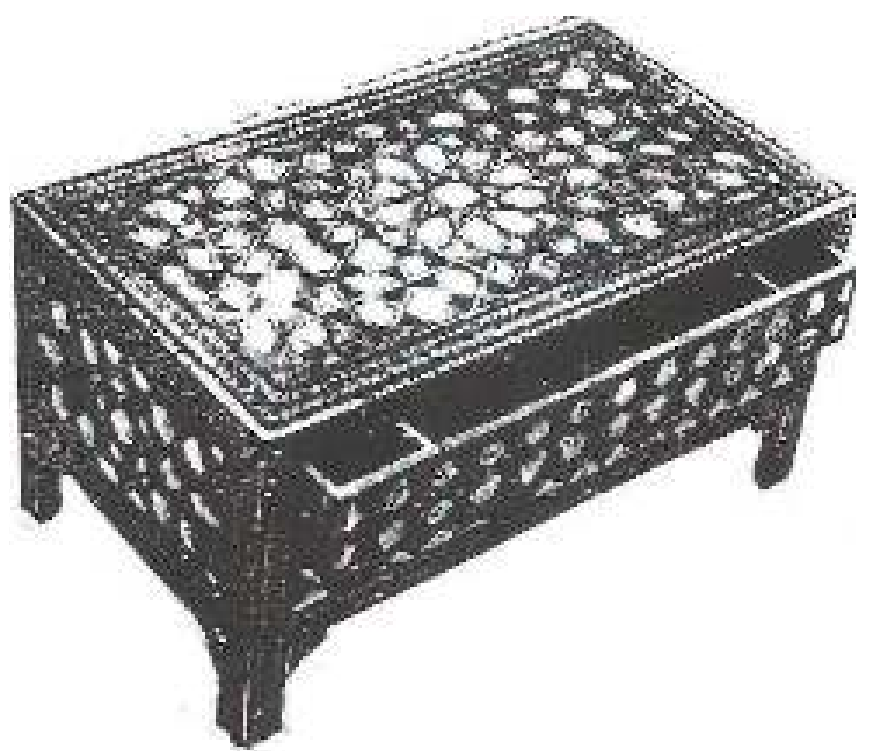

Fig. 5- Coffre de bijoux "šakmağiyya" - époque Ottomane (13 H./ 19 J.C.) Musée de l'art Islamique n 4607

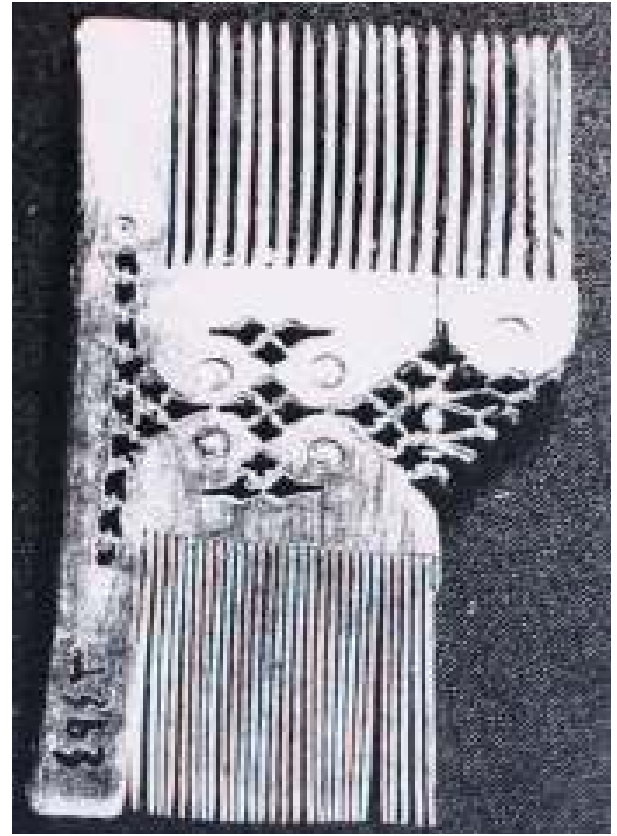

Fig. 6- Peigne en bois - époque Fatimide (3-4 H./ 9-1o J.C.) Musée de l'art Islamique $n^{\circ} 4943$ 


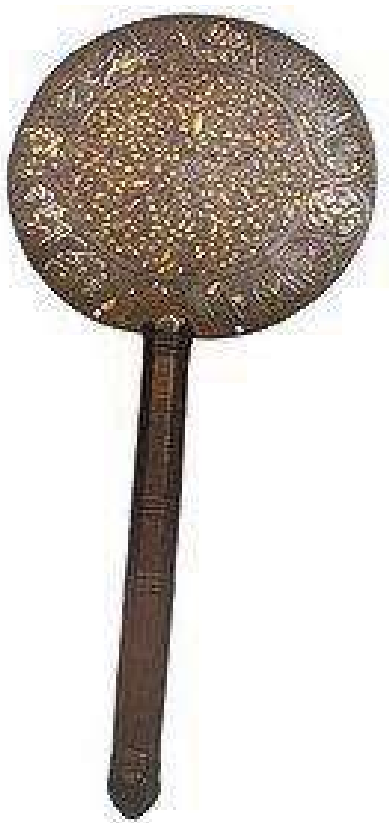

Fig.7- Miroir en cuivre - époque Mamelouke

Musée de l'art Islamique $n^{\circ} 13969$

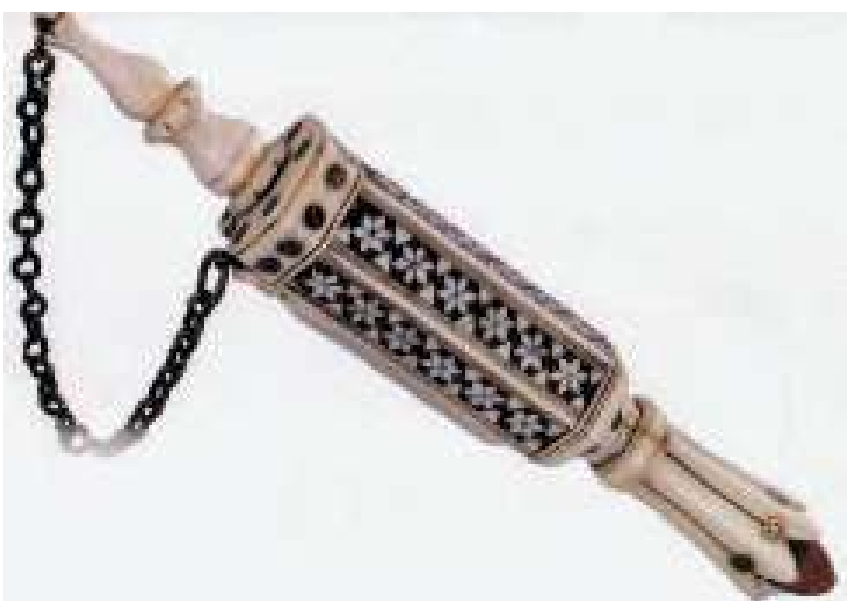

Fig. 8- Bouteille de fard en ivoire incrustée d'or - époque Mamelouke Musée de l'art Islamique $n^{\circ} 4050$ 


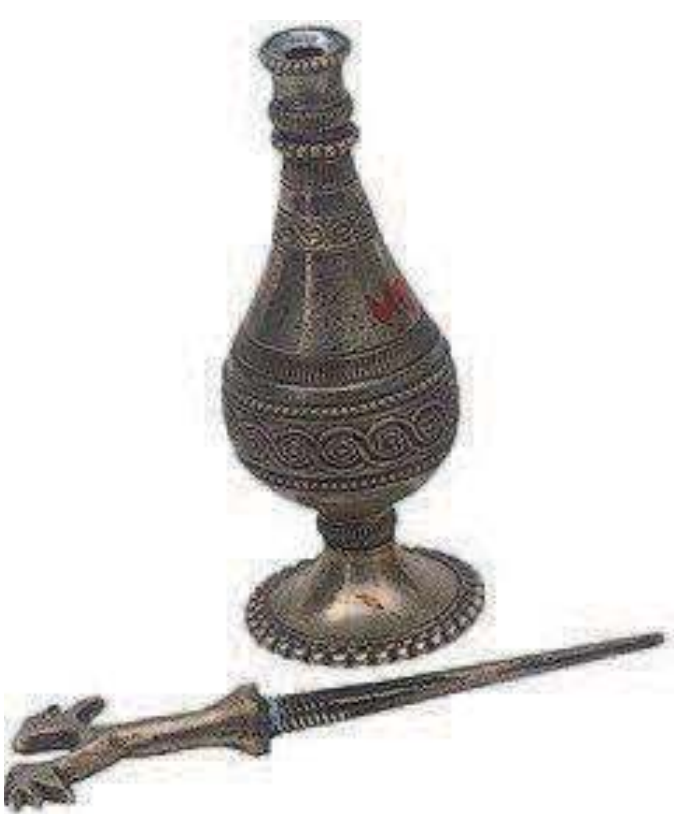

Fig. 9- Bouteille de fard en argent - époque Ottomane (12 H./18 J.C.) Musée d l'art Islamique $\mathrm{n}^{\circ} \mathbf{7 3 3 5}$

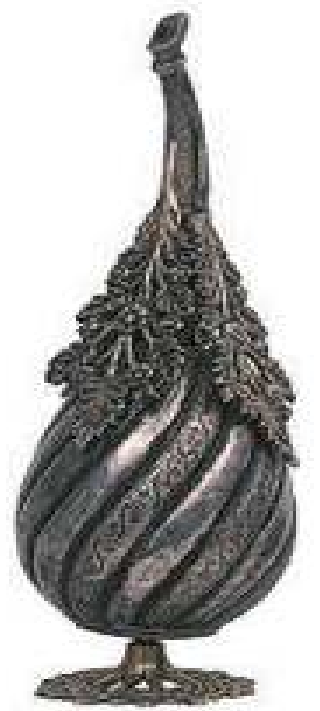

Fig.10 - Flacon de parfum en argent - époque Ottomane Musée de l'art Islamique $n^{\circ} 13556$ 


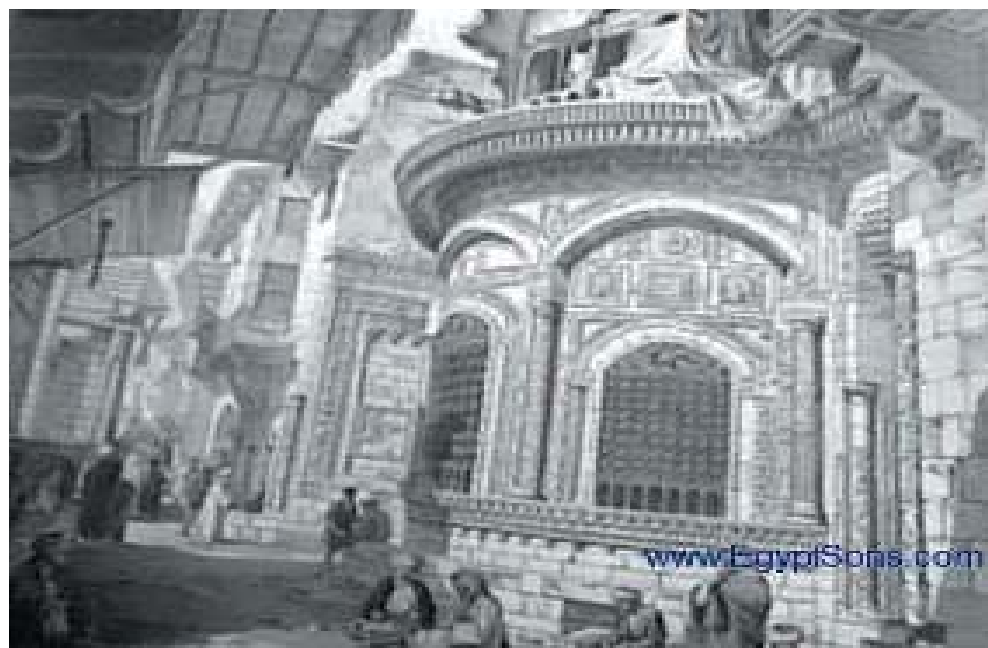

Pl. 1- Sabīl Ruqaya DūDū - façade

http://al-darb-al-ahmar.blogspot.com/p/blog-page_12.html

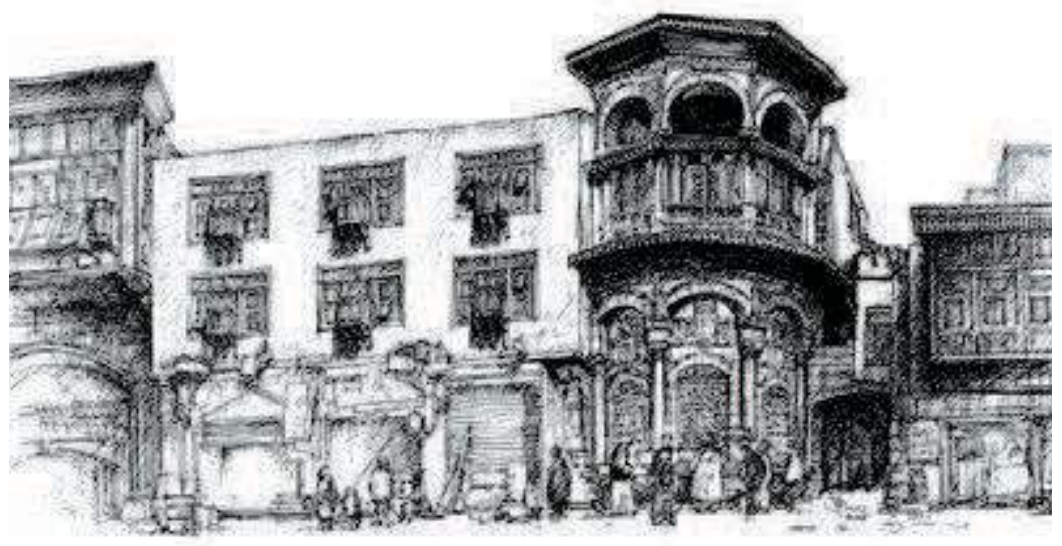

PI.2 - Caravansérail de Nafīsa al- Bayḍā- façade http://www.msobieh.com/akhtaa/viewtopic.php?f=21\&t=10346 